\title{
LA AUTORÍA A DEBATE: TEXTUALIZACIONES DEL CUERPO-CORPUS (UNA INTRODUCCIÓN TEÓRICA) ${ }^{1}$
}

\author{
Aina PÉREZ FONTDEVILA y Meri TORRAS FRANCÈS \\ Universitat Autònoma de Barcelona
}

\begin{abstract}
El corpus: jes una hermosa idea! A condición de que se admita leer en el corpus el cuerpo: ya sea que en el conjunto de textos retenidos para el estudio (y que forma el corpus), se busque ya no sólo la estructura, sino las figuras de la enunciación; ya sea que se tenga con este conjunto algún nexo amoroso (sin el cual el corpus no es más que un imaginario científico)
\end{abstract}

Roland Barthes

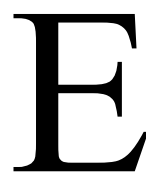

sta cita indudablemente hermosa, firmada por el que había sido el «gran parricida» de nuestro objeto/sujeto de elección y de afección (en todos sus sentidos) -el concepto de autor, así como todas las resistencias que opone al concepto de concepto $^{2}-$ articula de modo sugerente los dos polos - cuerpo/corpus- alrededor de los cuales se ha centrado el proyecto «Corpus Auctoris», dando lugar, entre otras actividades, al III Congreso Internacional Los Textos del Cuerpo. «El caleidoscopio autorial: textualizaciones del cuerpo-corpus» (algunas de cuyas intervenciones, reelaboradas, conforman este dossier ${ }^{3}$ ) o a la antología de traducciones Los papeles del autor/a. Teorías sobre la autoría literaria (Pérez Fontdevila y Torras Francès, 2015).

Como estos proyectos y actividades, el dossier «La autoría a debate» parte de una evidencia, un deseo (como mínimo) y una necesidad: la importancia de los estudios en torno a la figura autorial en otros foros académicos (el anglosajón, pero fundamentalmente el francófono); la voluntad de contribuir en alguna medida a su articulación, proponiendo un enfoque aparentemente sesgado o

\footnotetext{
${ }^{1}$ Este dossier monográfico ha sido llevado a cabo gracias al proyecto «¿Corpus Auctoris? Análisis teórico-práctico de los procesos de autorización de la obra artístico-literaria como materialización de la figura autorial» (FFI2012-33379), que se enmarca dentro del grupo de investigación consolidado Cuerpo y Textualidad (2014 SGR 1316).

${ }^{2}$ Recordemos la reflexión de Jacques Derrida en Las muertes de Roland Barthes (1981) acerca de la noción de punctum, desarrollada por Barthes en La cámara lúcida (1980) en estrecha relación con la de biografema (Barthes, 1971): «el punctum no se somete completamente al concepto, si entendemos por ello una determinación predictible, disponible y oponible. Ese concepto del fantasma es tan poco aprehensible, en persona, como el fantasma de un concepto. Ni la vida ni la muerte, sino el asedio del uno por el otro» (Derrida, 1981: 57).

${ }^{3}$ Este congreso fue celebrado en la Universidad Autónoma de Barcelona del 2 al 5 de diciembre de 2014. Hemos reunido otros artículos derivados de las ponencias allí presentadas en otros dos dosieres: uno en torno a autoría y cuerpo (Estudios. Revista de Investigaciones Literarias y Culturales, 2015) y otro en torno a autoría y género (Mundo Nuevo. Revista de Estudios Latimoamericanos, 2015), ambos coordinados por las editoras de este monográfico en colaboración con Eleonora Cróquer y ambos centrados en la aplicación de los Estudios Autoriales a un corpus hispánico e iberoamericano. Próximamente aparecerá también un volumen de actas.
} 
periférico, pero tal vez -y quizás por ello mismo- de alcance transversal (su abordaje a partir de la reflexión en torno al cuerpo, de la que el grupo Cuerpo y Textualidad lleva ocupándose desde 2005); y la difusión insuficiente de estas perspectivas en el ámbito académico hispánico.

\section{Algunos apuntes sobre Estudios Autoriales}

La cita de Roland Barthes - de este Roland Barthes cuya firma abismada (Roland Barthes por Roland Barthes, 1975) no es la misma que había rubricado «La muerte del autor» (1968)- nos permite situar esa primera evidencia, en tanto muestra que, incluso dentro de la propia trayectoria del teórico (Diaz, 1984, 1993 y 1996), ese acta de defunción tuvo consecuencias paradójicas: puso el concepto de autoría en el centro de la escena teórica, invitando a repensar, entre muchos otros aspectos, la relación entre «el-hombre-y-la obra», a menudo entendida como evidente y transparente (y lineal, teleológica), o el estatuto «tiránico» del Autor-Dios. Como es sabido, encontró una respuesta casi inmediata en el artículo «Qué es un autor», de Michel Foucault (1969), que abría a su vez un amplio campo de estudio genealógico respecto a una figura en adelante entendida como una «función del texto» y como un producto de la Modernidad. Sin embargo, fue décadas más tarde cuando la provocación de Roland Barthes encontró las reacciones más fructíferas y articuladas, hasta el punto de que los estudios en torno a la figura autorial son actualmente uno de los campos más prolíferos de la teoría literaria, en su cruce con disciplinas como el análisis del discurso o la sociología del arte y de la literatura ${ }^{4}$.

La noción de autor se ha revelado clave para dar cuenta del funcionamiento del texto en un sentido amplio, es decir, entendiendo como texto todos aquellos elementos que contribuyen a la producción de un significado histórica y socialmente situado. Las aportaciones más destacadas en este sentido teorizan la figura autorial como producto en sí mismo textual (es decir, como un corpus conformado por un conjunto de textos heterogéneos: biográficos, académicos, visuales, autográficos, etc.); como construcción significativa que no se sitúa fuera y antes de la «obra en sí» sino que, como sugería Itamar Even-Zohar en 1997, constituye uno de los productos del sistema literario. La figura autorial así entendida contribuye a la producción de sentido como un intertexto fundamental en la «lectura individual» (si es que tal sintagma tiene sentido), pero también en la circulación de la obra que lleva su nombre (y de los géneros discursivos con los que se vincula) y en su situación -central o periférica, canónica o marginal- en el campo literario, tal y como ya apuntara Foucault (1969). Por otro lado, estas construcciones autoriales dan cuenta de los discursos culturales acerca de la autoridad, la creación y la legitimidad literarias y artísticas en un determinado contexto socio-histórico, esto es, se producen en diálogo con posiciones autoriales preestablecidas, que se materializan en estereotipos y tópicos acerca de la autoría y de la creación histórica y culturalmente variables, mediante los cuales se regula el acceso de los sujetos al campo literario.

\footnotetext{
${ }^{4}$ En relación a las perspectivas discursivas y sociológicas, es imprescindible la antología La invención del autor, compilada por Juan Zapata (2014), que reúne textos de Michel Foucault, Dominique Maingueneau, Ruth Amossy, Jérôme Meizoz, Alain Vaillant, Pascal Durand, Pascal Brissette, Nathalie Heinich, Denis Saint-Amand, Jean-Pierre Bertrand, Sylvie Ducas, Carlos Builes, Kristine Vanden Berghe, Alejandro Quin y el mismo Zapata. Véase también Zapata (2011).
} 
Así pues, lo que podríamos convenir en llamar Estudios Autoriales recuperan la pregunta acerca de la relación entre autor/a y obra mediante una complejización de la noción de autor que lo considera más allá de su realidad fáctica, como sujeto real, para retomarlo como producto textual e histórico, cuyo análisis (y el análisis de cuyas puestas en escena), ha demostrado ser fundamental para una comprensión del hecho literario y artístico que deconstruya y supere toda oposición entre texto/contexto u obra/institución (Maingueneau, 2004).

\section{Perspectivas «teórico-filosóficas» $\mathbf{y}$ «genealógicas»}

Cualquier descripción sucinta y generalizante de un panorama teórico tan vasto está abocada a la inexactitud, la parcialidad e incluso a cierta tergiversación ${ }^{5}$. Asumiéndolo siempre, y sabiendo también que no se trata de compartimentos estancos sino de perspectivas en necesaria y continua relación, nos atrevemos a perfilar tres líneas alrededor de las cuales podrían agruparse las investigaciones que ha suscitado el interés por el autor y que dan cuenta de la multiplicidad de problemáticas y ámbitos de estudio, más o menos desarrollados, que abre el retorno teórico de la instancia autorial.

En primer lugar, y muy a menudo en relación con los textos «fundacionales» de Barthes y de Foucault, encontramos lo que podríamos considerar una perspectiva teórico-filosófica, que revisa y dialoga con la obra de estos y otros autores, especialmente (post)estructuralistas, en relación a cuestiones directamente vinculadas con la autoría o con conceptos afines y útiles para su abordaje. Tal es el caso, por ejemplo, de la exhaustiva discusión que lleva a cabo Séan Burke en The Death and Return of the Author (1998) en cuanto al corpus de Barthes, Foucault o Derrida; de la imprescindible reflexión en torno al concepto de firma que realiza Peggy Kamuf en Signature pieces (1988) desde una perspectiva fundamentalmente derrideana; o, en la estela de Foucault, del análisis de Gérard Leclerc (1998) en torno al nombre de autor ${ }^{6}$ como marca comercial, entre otros aspectos derivados de su estudio teórico-genealógico de la autoridad ${ }^{7}$.

Aunque probablemente José-Luis Diaz y Dominique Maingueneau discutan con razón su inclusión en esta línea, nos parece que sus trabajos sobre Barthes y Proust, respectivamente, son de obligada mención aquí. Como señalábamos al inicio, el trabajo de Diaz (1984, 1993 y 1996) demuestra la «constancia ejemplar» con que Barthes pensó la cuestión del autor más allá de su decreto de muerte, evidenciando hasta qué punto se adelanta a algunas de las aproximaciones más recientes. Emprende, además, un análisis de la misma construcción de Barthes como autor -más cercana a la del escritor que a la del intelectual precisamente porque éste «no conoce el secreto del deseo, ni esa aventura

\footnotetext{
${ }^{5}$ Para un panorama más exhaustivo, aunque no por ello menos aquejado de estas dolencias, remitimos al estudio introductorio de la antología Los papeles del autor/a (Pérez Fontdevila y Torras Francés, 2015). Allí podrá encontrarse también una selección bibliográfica que da cuenta de su diversidad.

${ }^{6}$ La cuestión de la firma y del nombre de autor es enfocada también desde el análisis de la pseudonimia en volúmenes como La Pseudonymie dans la littérature française. De François Rabelais à Éric Chevillard (Martens, 2016), actualmente en prensa.

${ }^{7}$ Pusimos en diálogo algunas de estas propuestas en el artículo de Pérez Fontdevila «Re/producir la cultura. En torno a las firmas de A paixão segundo G.H» publicado en el monográfico sobre «Autoría y cuerpo» de la revista Estudios (Cróquer, Pérez y Torras, 2015).
} 
erótica y ni siquiera el lenguaje que es lo propio del escritor» (1993: 82) ${ }^{8}$-, trabajando la paradoja que implica el hecho de que aquellos que deconstruyeron más contundentemente la autoría sigan apareciendo como autores en el campo cultural, sujetos a las escenificaciones, mitificaciones y (des)figuraciones que éste impone. Por su parte, Dominique Maingueneau (2006) nos muestra la estrecha relación existente entre los planteamientos de Proust en Contra Saint-Beuve y la Nueva Crítica: la tesis proustiana de los dos yoes del escritor - un «yo profundo», interior, fuente de la obra; y un «yo exterior», superficial, social, el único al que puede acceder la crítica biográfica a lo SainteBeuve- es solidaria de la ruptura entre Texto y contexto que preconiza el estructuralismo y que el «giro discursivo» en los estudios literarios permite suturar, como decíamos al inicio, «restituyendo las obras al espacio que las hace posibles, donde son producidas, evaluadas, difundidas, almacenadas, reutilizadas, etc.» (Maingueneau, 2006: 47).

En segundo lugar, podemos señalar una perspectiva primordialmente genealógica (parte del mismo Contra Saint Proust podría situarse también aquí) que revisa y da cuenta de los procesos históricos e ideológicos mediante los cuales se construye el concepto de autor artístico y literario en Occidente. Aunque los trabajos en este sentido son innumerables, podemos mencionar algunas investigaciones imprescindibles como las de Martha Woodmansee sobre la construcción del autor (Woodmansee y Jaszi, 1994) -y específicamente de la figura del genio (Woodmansee, 1984)- en relación a la institución de los derechos autoriales, o los diversos estudios de Nathalie Heinich sobre la categoría de artista en «régimen de singularidad» (2005), que Jean-Marie Schaeffer llama, por su parte, «régimen de originalidad» (1997). Además de poner en evidencia la necesidad de abordar conjuntamente las autorías literarias y artísticas, sus trabajos arrojan luz sobre las condiciones de emergencia de los valores comúnmente asociados a la creación - tales como don, vocación, talento, interioridad, excepcionalidad, singularidad, autenticidad, y un largo etcétera (Heinich, 2005; Schaeffer, 1997; Heinich, Schaeffer y Talon-Hugon, 2014)- y constituyen referencias ineludibles para la comprensión del campo cultural en la actualidad: de hecho, la misma Heinich se ha ocupado profusamente de la categoría de escritor y de artista en la contemporaneidad, en libros especialmente relevantes para lo que nos ocupa como Etre écrivain (2000).

\section{Ethos, imagen de autor, escritor imaginario y postura autorial}

La siguiente línea que queremos mencionar es, de hecho, la que pone en evidencia de forma más clara el carácter artificial de nuestra tripartición, puesto que engloba propuestas que, como las anteriores, están fundamentadas en el estudio empírico de períodos históricos, figuras autoriales y corpus textuales concretos, en diálogo con algunas de las «perspectivas teórico-filosóficas» referidas en primer lugar y con otras disciplinas, también mencionadas, como el análisis del discurso o la sociología.

\footnotetext{
8 «He escrito, tengo pues alguna oportunidad de ser situado en el campo del placer, y no en el de la autoridad», afirma Barthes (apud. Diaz, 1993: 84).
} 
Por otro lado, buena parte de los estudios que situamos aquí nos enseñan también que cualquier investigación sobre la figura autorial que parta exclusivamente de la contemporaneidad (empezando por las que firmamos las autoras de este artículo) corre el riesgo de tomar por novedosos y específicos aspectos con un largo recorrido: basta leer el trabajo de José-Luis Diaz aquí publicado para darnos cuenta de que el carácter caleidoscópico de la figura autorial, su condición espectral o incluso la espectacularización de la que es objeto (y agente) el escritor en nuestro «régimen mediático» (Heinich, 2012) están lejos de ser propias de los siglos XX y XXI.

Sin embargo, merecen mención a parte porque proporcionan valiosas herramientas para un análisis de la autorialidad que erosiona lo que podríamos considerar su sentido común, es decir, su asociación con nociones tales como unidad, identidad, autonomía, soledad, autogenética, paternidad ${ }^{9}$ o anterioridad y exterioridad al texto. Como ya sugeríamos en los párrafos iniciales, y como trataremos de exponer ahora de un modo más concreto, todas estas perspectivas abordan la autoría como un entramado textual heterogéneo ( $v s$. la unidad e identidad que presupone su concepción tradicional), producto de la obra ( $v s$. la anterioridad y la exterioridad y sus nociones asociadas, tales como la de paternidad) y de los diversos procesos colectivos inherentes a la literatura entendida como dispositivo comunicativo, institucional e identitario ( $v s$. la autonomía, la autogenética o la soledad que se suponen necesarias para la creación artística).

Para empezar, podemos situar aquí la reelaboración del concepto de ethos, procedente de la retórica clásica, que han llevado a cabo Ruth Amossy (1999) y Dominique Maingueneau (1993, 2004, $2009)^{10}$ y que permite analizar las figuras de enunciación de los textos y paratextos literarios (y, en general, de los productos discursivos) superando las distinciones tradicionales entre narrador/ yo poético/ autor real, etc., deudoras de la división proustiana entre yo profundo y yo exterior a la que nos referíamos anteriormente (y de la que deriva también la separación que acabamos de hacer entre texto y paratexto). Vinculada a la noción de ethos, cabe mencionar la de posicionamiento (Maingueneau, 1993 y 2004), entendido como la «identidad enunciativa» que se construye en relación, por ejemplo, a las doctrinas estéticas, las definiciones dominantes de «autoridad enunciativa», la inclusión o exclusión de determinados intertextos, las elecciones de género o de códigos lingüísticos, etc. La creciente atención prestada al «ethos previo»o «prediscursivo» (Amossy, 1999; Maingueneau, 2004) (el que se desprende de las imágenes del locutor «fuera» del texto, vinculadas a estereotipos autoriales compartidos) como elemento fundamental en la interpretación del ethos textual, cristaliza y se amplifica en la noción de «imagen de autor», suerte de síntesis de los ethos intra y extratextuales que Maingueneau sistematiza en el artículo que hemos traducido para este dossier ${ }^{11}$.

\footnotetext{
${ }^{9}$ Y no maternidad: como muestra Standford Friedman (1987), es bien diferente el uso de las metáforas paternales y maternales aplicadas a la creación literaria y artística.

${ }^{10}$ Tanto en este como en los casos que siguen, señalamos sólo las publicaciones más relevantes. Para el concepto de ethos, véanse también las traducciones de Maingueneau publicadas en 1996 y 2010.

${ }^{11}$ Véase también, entre otros, Maingueneau (2009) y Amossy (2009), ambos recogidos en un monográfico sobre ethos e imagen de autor de la revista Argumentation et Analyse du Discours (Bokobza Kahan y Amossy, 2009) y traducidos por Juan Zapata en su antología La invención del autor (2014).
} 
Por su parte, José-Luis Diaz (2007) considera la autoría como dispositivo identitario en el cual se superponen lo real, lo textual y lo imaginario (vinculado al deseo y al fantasma) ${ }^{12}$, construyendo un «espacio-autor» de carácter estereoscópico. En diálogo con propuestas anteriores como las de Paul Bénichou (1973), Alain Viala (1985), Daniel Oster (1983 y 1997) o el propio Barthes, Diaz plantea la noción de escritor imaginario, que entiende la instancia autorial como un «mecano»o «puzzle» (Diaz, 2007) configurado tanto por los propios escritores/as (en estrecha e inevitable relación con posiciones prêt-à-être auteur que se articulan en escenografías autoriales epocales y de uso colectivo ${ }^{13}$ ) como desde la recepción, en la cual la figura autorial se (re)construye a través del montaje móvil y cambiante de sus piezas: paratextos tales como prefacios y dedicatorias; manifiestos o escritos sobre otros escritores/as; biografías, críticas académicas y periodísticas; u (otros) textos culturales vinculados a la escenificación de la autoría, como los «dispositivos religiosos y legendarios» que dan cuenta de la sacralización (Bénichou, 1973) y de la vedetterización del escritor (Diaz, 2007), ya (e incluso antes) del período romántico. El escritor imaginario es, pues, el producto de las «elecciones» del candidato a escritor ${ }^{14}$, de sus reconfiguraciones a lo largo de su trayectoria autorial y del remodelaje que, en vida y póstumamente, realiza el lector en función de las escenografías autoriales que, a su vez, tenga disponibles.

En relación con estas propuestas, con las que presenta no pocas coincidencias, Jerôme Meizoz (2007 y 2011) articula la noción de postura, cuyo alcance rebasa el marco en el cual fue elaborada (fundamentalmente, el análisis de la «presentación de sí» en textos autobiográficos), permitiendo dar cuenta tanto de las imágenes del enunciador que se desprenden de los textos presentados y leídos como «ficcionales» (su ethos textual, por tanto, vinculado a una «tonalidad» [Meizoz, 2007] o «vocalidad», para utilizar el término de Maingueneau [2004]) como de las que se construyen en sus puestas en escena mediáticas. La postura articula, así, una perspectiva interna y otra externa, vinculada a la «presentación de sí», a menudo espectacularizada, «en los contextos en los cuales la persona encarna la función-autor» (Meizoz, 2007: 23). Aunque es definida como «la manera singular de ocupar una “posición” en el campo literario» (Meizoz, 2007: 18), el trabajo de Meizoz es especialmente atento a su carácter colectivo, en tanto la postura implica «variaciones individuales» de un «repertorio proporcionado por la tradición» (Meizoz, 2007: 189) y una puesta en escena (o performance [2011: 91]) indisociable del reconocimiento y la interpretación por parte del público lector y espectador (en algunos aspectos, enlaza, pues, con el escritor imaginario o la escenografía autorial propuesta por Diaz $)^{15}$.

\footnotetext{
${ }^{12}$ Sobre la posibilidad de distinguir claramente estas tres instancias, el mismo Diaz escribe: «Imposible pues aislar una instancia "real", social o biográfica, sin "construirla" más o menos inocentemente en función de un imaginario. [...] Imposible igualmente aislar una instancia puramente textual desde que se constata que esta elección exclusivamente formal en apariencia $[\ldots]$ está en correlación con una elección socio-profesional [...] y la elección de una identidad especular» (2007: 44).

${ }^{13}$ Sobre las escenografías autoriales románticas, véase también Diaz (2013), entre muchos otros trabajos del mismo autor.

${ }^{14}$ En la relativa medida en que puedan considerarse como tales, es decir, vinculadas con la elección o la agencia: preexisten al sujeto y le son necesarias para devenir reconocible en la escena literaria.

${ }^{15}$ Todas estas propuestas han generado numerosos debates académicos y otros tantos estudios de caso, cuya diversidad nos impide enumerarlos aquí. Remitimos a los números monográficos de la revista COnTEXTES. Revue de sociologie de la
} 


\section{El autor como artefacto cultural}

Partiendo en muchos casos de la concepción caleidoscópica del autor que, en diversos modos, comparten estas propuestas, es palpable un interés creciente por el análisis específico de las diversas piezas que lo conforman, con especial énfasis en aquellos aspectos que comportan su puesta en escena en el espacio social (Meizoz, 2015). Siguiendo a Nathalie Heinich (2012) podemos afirmar que la atención está centrada en la representación de los escritores/as y artistas en «régimen mediático», privilegiando ámbitos de estudio tales como la representación fotográfica y audiovisual (Martens y Reverseau, 2012; Bertrand, Durand y Lavaud, 2010; Dewez y Martens, 2009) o los géneros de la entrevista (Martens y Meurée, 2015 y 2014; Yanoshevsky, 2014), en los cuales se pone en evidencia de forma más clara que el estatuto de autor tiene un carácter negociado: depende del reconocimiento y autorización cultural y, por lo tanto, es indisociable de la incorporación y escenificación de atributos autoriales que permitan tales procesos de contrafirma, para decirlo en términos derrideanos. Desde esta perspectiva, la autoría puede abordarse desde la noción de performance, como ya sugeríamos con Meizoz en el apartado anterior y como propone de un modo más sistematizado el grupo Reaserch of Authorship as Performance, retomando el concepto desde las propuestas de Austin, Turner o Butler (Berensmeyer, Buelens y Demoor, 2012) ${ }^{16}$.

Todo ello apunta hacia la consideración del autor (de su corpus pero también y sobre todo de su cuerpo) como objeto o artefacto cultural, tal y como proponen David Martens (2012) o Eleonora Cróquer (2005, 2009 y 2012). La propuesta de Cróquer, centrada en la noción de caso de autor, es una de las únicas aportaciones que se han articulado específicamente a partir del estudio de un corpus literario y artístico hispánico ${ }^{17}$. Planteada a partir del análisis de referentes artísticos de la Modernidad de América Latina (Delmira Agustini, Teresa de la Parra, Armando Reverón, Frida Kahlo o Clarice Lispector), su propuesta da cuenta de la imparable producción discursiva alrededor de estas figuras, siempre asociadas con la otredad (el loco, la femme fatal, la extranjera, etc.), que las plantea como caso para el investigador, como un enigma a ser descifrado a partir de las puestas en escena de la vida como obra y de la obra como vida; en las múltiples escenificaciones, pues, del cuerpo del autor/a y de sus relatos biográficos, auto y heterográficos ${ }^{18}$.

\section{Entre el cuerpo y el corpus}

Decíamos antes que nuestro enfoque sesgado y periférico de la autorialidad se articulaba alrededor del concepto de cuerpo, cuya excentricidad esperábamos compensar por su alcance

littérature, dedicados a las nociones de postura (A.A.V.V, 2011) y ethos (Dhondt et al, 2013), así como al dosier especial, ya citado, sobre ethos e imagen de autor de la revista Argumentation et Analyse du Discours (Bokobza Kahan y Amossy, 2009).

${ }^{16}$ Esta perspectiva, en relación con las precedentes y con el estatuto problemático del cuerpo y del género en la representación autorial (véase el siguiente apartado), la desarrolla Pérez Fontdevila en su tesis doctoral.

${ }^{17}$ Cabe mencionar también el trabajo de Julio Premat (2009) y, en diálogo con Cróquer, el de Núria Girona (2008).

${ }^{18}$ Además de los trabajos referidos en la bibliografía (Cróquer, 2005, 2009 y 2012), hemos publicado otros dos artículos de Eleonora Cróquer sobre la cuestión: «Curriculum Vitae», en la antología Los papeles del autor/a (Pérez Fontdevila y Torras Francès, 2015) y «Ese entrañable objeto del deseo social o lo que algunos de nuestros “casos de autor" demuestran», en el monográfico ya referido para la revista Estudios (Cróquer, Pérez y Torras, 2015). 
transversal: el cuerpo no aparece precisamente como un concepto central en nuestra tradición de pensamiento, pero por ello mismo quizá resulte fundamental como su exterior constitutivo, permitiendo dar cuenta de problemáticas relevantes en relación a la autoría, como ocurre con la cuestión más general de la identidad (de la cual, como hemos ido sugiriendo, aquélla podría considerarse una manifestación concreta). Sin ánimo de sistematizarlas con exhaustividad, sí quisiéramos apuntar a algunas de las perspectivas que abre $-y$ de las tensiones que resultan de- la articulación entre autoría y corporeidad.

En primer lugar, es evidente que muchas de las piezas del «mecano autorial» que hemos enumerado -y especialmente las que más atraen la atención en la actualidad- implican la representación del autor/a como ser encarnado, lo que supone un desafío al rechazo de la imagen que ha acompañado tradicionalmente buena parte de las posturas autoriales (Ortel, 2002; Heinich, 2012) y que nos parece vinculado a la denostación del cuerpo ( $v s$. el espíritu, el intelecto, la mente, lo inmaterial, lo ideal, etc.) que caracteriza en gran medida el pensamiento occidental. De hecho, esas representaciones encarnadas entran en conflicto con una de las principales operaciones de delegación corporal que ha producido la institución literaria y artística: precisamente la sustitución del cuerpo del autor en tanto organismo de carne y hueso por un dispositivo no menos organizado, coherente y funcional, la obra o corpus ${ }^{19}$. Éste se concibe como el verdadero cuerpo del escritor o del artista en cuanto tal, puesto que son la materialización del carácter, la idiosincrasia o el temperamento (siempre asociados al fuero interno, es decir, siempre concebidas como instancias espirituales o intelectuales) que le convierten en autor. La representación iconográfica implica dar a ver como cuerpo una instancia que se concibe como esencialmente inmaterial, pero que, sin embargo, viene sometiéndose a ese «servicio militar social» de la Imagen (Barthes, apud. Diaz, 2007: 22) desde mucho antes de que la aparición de la fotografía inaugurara la era de la reproducción y difusión imagística en la que estamos inmersos (Heinich, 2012): no sólo la pintura o la escultura ya estaban al servicio de la representación del cuerpo autorial - con su insistencia en determinadas partes anatómicas como el rostro, los ojos o las manos-, sino que incluso la empresa biográfica - a priori textual en un sentido estricto- se concibió, desde el inicio, en relación a las artes iconográficas ${ }^{20}$.

En segundo lugar, hemos insistido repetidas veces en que gran parte de las propuestas fundamentales en Estudios Autoriales abordan la figura del autor/a como un producto textual e histórico. Desde este punto de vista, cabe atender a los «sujetos reales» en la medida en que sus cuerpos o sus vidas son textualizados en las representaciones y escenificaciones que hemos mencionado. Desde el momento en que estos cuerpos y estas vidas son representados como cuerpos y vidas de escritor/a, la categoría de sujeto real deja de ser operativa y debe sustituirse por la de actor o auctor $\left(\right.$ Maingueneau ${ }^{21}$ ). Sin embargo, en las propuestas de Diaz, Maingueneau y Meizoz se apunta al hecho de que las posturas y escenografías autoriales y las normas y valores que las atraviesan determinan un

\footnotetext{
${ }^{19}$ Planteamos algunas de estas cuestiones en el artículo de M. Torras «Y el verbo se hizo carne. Vías de encarnación de un corpus-cuerpo autorial», publicado en el monográfico ya referido para la revista Estudios (Cróquer, Pérez y Torras, 2015).

${ }^{20}$ Esto nos parece colegir de los ejemplos que recoge Diaz (2012).

${ }^{21}$ Véase el artículo que publicamos en este monográfico.
} 
habitus, un hexis corporal (Bourdieu, apud. Maingueneau, 2004) o incluso una somática del cuerpo (Fabre, apud. Diaz, 2007), configurando los comportamientos, actitudes corporales, elecciones y experiencias vitales de los «sujetos reales», que podríamos considerar textualizados «de origen»: para citar un ejemplo reciente, José-Luis Diaz (2015) analiza de qué modo los escenarios autoriales engendran lo que denomina prêt-à-vivre. Esta perspectiva permite abordar la autoría como una posición-sujeto, como ya sugiriera Diana Fuss (1989) retomando el concepto de Foucault y Spivak, así como vincularla nuevamente a la noción de performatividad desarrollada por Judith Butler (1990, 1997a y 1997b) en relación al género (creemos especialmente útil a este respecto su revisión de los conceptos de sujeción e interpelación, propuestos por Foucault y Althusser, respectivamente) ${ }^{22}$.

En tercer lugar, y en relación con esta última sugerencia, podemos considerar las diversas figuras autoriales que los candidatos a autor deben encarnar (adoptándolas, negociándolas o subvirtiéndolas) como entramados normativos vinculados tanto a los valores del arte (los que determinan sus fronteras en un momento determinado) como a los valores sociales que regulan también la construcción de los sujetos. De hecho, valores artísticos y valores sociales son indisociables: puede trazarse una correspondencia entre la construcción del sujeto descorporeizado vinculado a la tradición platónica y cartesiana y la individualidad ( $v s$. la colectividad), la autonomía ( $v s$. la dependencia o la sujeción), la soledad y la singularidad ( $v s$. la comunidad), la originalidad ( $v s$. la repetición o la reproducción) o la interioridad ( $v s$. el cuerpo) que se conciben como condiciones, definiciones u orígenes necesarios de la creación artística (Schaeffer, 1997). Frente a éstos, la obra producida por sujetos asociados con el cuerpo (por ejemplo, aquellos marcados por el género o la etnia), es penalizada en el campo literario en tanto portadora de la experiencia corporal de su creador/a: es leída como una muestra de la experiencia del colectivo al que pertenece (frente a la pretendida universalidad de lo literario, representativo de lo humano) y en su ligazón con una realidad (personal, corporal, comunitaria) que le restará creatividad (entendiendo la verdadera creación como creación ex nihilo) y, por lo tanto, valor literario o artístico 23 .

Esta red conceptual permite explicar a su vez el valor otorgado a determinados géneros textuales: entre los géneros autográficos, por ejemplo, la autobiografía, expresión de una individualidad singular, se opondrá al testimonio, entendido como descripción de una experiencia colectiva, cuyo estatuto literario ha estado en disputa durante mucho tiempo por esta misma razón ${ }^{24}$. Así pues, existen correlaciones entre la consideración (artística o no) y el posicionamiento (más o menos central o marginal) de los géneros literarios y artísticos en el campo cultural (e incluso entre la interpretación de un determinado texto como perteneciente a este o aquel género) y las marcas corporales de los sujetos que ocupan (o se prevé que ocupen) su función-autor. De este modo, el análisis de las relaciones

\footnotetext{
${ }^{22}$ En relación a este punto y al siguiente, remitimos al artículo «Ninguna voz es transparente. Autorías latinoamericanas para un corpus visibilizador», introducción al monográfico ya citado para la revista Estudios (Cróquer, Pérez y Torras, 2015). Asimismo, desarrollamos estas perspectivas de un modo más exhaustivo en la antología Qué es una autora. Encrucijadas teóricas entre género y autoría, que publicaremos próximamente en la editorial Icaria (2016).

${ }^{23}$ De ahí que, pese a que nuestro enfoque no pierde de vista una perspectiva de género, no lo reflejemos en el lenguaje utilizado en esta introducción: el concepto de autor o de creador no equivale al concepto de autor/a o creador/a.

${ }^{24}$ Noemí Acedo Alonso analiza el género testimonial desde estas y otras perspectivas en su tesis doctoral.
} 
entre autoría y cuerpo (vinculado a su vez a nociones tales como «vida»o «experiencia») permite dar cuenta de los mecanismos que regulan las posturas autoriales o los posicionamientos en el campo literario de determinadas figuras, obras y géneros discursivos.

\section{Este monográfico: «La autoría a debate: textualizaciones del cuerpo-corpus»}

Los artículos reunidos en este monográfico se hacen eco de las problemáticas que hemos intentado plantear a vista de pájaro, desarrollando algunas de las líneas expuestas o desplegando mediante estudios de caso éstas y otras perspectivas que la cuestión del autor pone sobre la mesa, dando fe de la multiplicidad de investigaciones que convoca.

Abren el monográfico los artículos ya mencionados de Dominique Maingueneau y José-Luis Diaz, que nos permiten comprender, por un lado, el amplio alcance de la noción de imagen de autor y, por el otro, la complejidad de las relaciones entre cuerpo y corpus en el período romántico, un período que, como decíamos, se demuestra revelador para los abordajes contemporáneos también en este aspecto. Dialogando con ambos artículos, Celina Moreira de Mello e Irineu E. Jones Corrêa se centran en esas relaciones en el mismo siglo XIX desde la perspectiva del análisis del discurso propuesta por Maingueneau: la primera, mediante el estudio del ethos proyectado en las ilustraciones de la revista L'Artiste como escenificaciones del cuerpo romántico; y el segundo, a través del análisis de los vínculos entre discurso pornográfico, romanticismo nacionalista y construcción autorial en el caso del poeta brasileño Bernardo Guimarães.

El artículo de Eleonora Cróquer trabaja sobre tres de sus casos de autor(a)-María Teresa Bombal, Frida Kahlo y Clarice Lispector- abordando las escenificaciones de su vida-obra en diálogo con Deleuze y Guattari, Lacan o Foucault y aplicando algunos de los conceptos a los que nos hemos referido, como el de ethos o postura. La productividad de este último se muestra en los dos artículos siguientes. El primero, de Meri Torras, emprende el análisis de una de esas piezas del «mecano» autorial en las que se representa la autoría encarnada: la fotografía y, más concretamente, la textualización de la postura como pose visual tal y como es expuesta en la novela Photo-Photo, de Marie Nimier. El segundo, de Juan Zapata, plantea el abordaje de la figura del traductor, tan a menudo invisibilizada y desautorizada, a partir de la noción de Meizoz en diálogo con otras propuestas fundamentales como las de Maingueneau y Heinich.

Los artículos de Aina Pérez, Ester Pino y Mayte Cantero retoman la figura de Roland Barthes desde diversas perspectivas, poniendo en evidencia que -como señalábamos- «La muerte del autor» está lejos de ser su última palabra sobre la cuestión y, especialmente, sobre el binomio cuerpo/corpus. Pérez nos propone un negativo de esta introducción, abordando la autoría desde una perspectiva corta de vista, (a)pegada a una fotografía de Roland Barthes y al hilo de algunas reflexiones de Jacques Derrida. Ester Pino analiza la vuelta a la autoría y la erotización del lenguaje en diversos textos del teórico, como El placer del texto, Roland Barthes por Roland Barthes o Fragmentos de un discurso amoroso. Finalmente, Mayte Cantero retoma algunas de la cuestiones que hemos planteado en relación a la autoría y el género, partiendo de las problemáticas que implica, desde un punto de vista feminista, 
la consideración de la escritura como un «lugar neutro» en el que «acaba por perderse» la «identidad del cuerpo que escribe», tal y como rezaba «La muerte del autor» (Barthes, 1968).

En relación con estos artículos, el siguiente bloque amplia la reflexión sumando las voces de otros nombres fundamentales de la filosofía y la teoría literaria contemporáneas. Tal es el caso del sugerente juego que nos propone García Hubard a partir de la lectura del «texto de Derrida» Et si les œuvres changeaient d'auteur?, publicado en 2010 bajo el nombre de Pierre Bayard. Por su parte, Begonya Sáez analiza la condición espectral del autor, también «presente» en el artículo de García Hubard, mediante una lectura detenida de ese otro gran texto fundacional de los Estudios Autoriales: «Qué es un autor», de Foucault. Finalmente, Andrés Armengol demuestra la pertinencia de abordar la autoría desde propuestas filosóficas centradas en la identidad: así, nos propone una reflexión acerca de conceptos tales como singularidad o vulnerabilidad en diálogo con Hanna Arendt, Adriana Cavarero o Alenka Zupancic.

La construcción de las figuras de enunciación en los textos literarios (y cinematográficos) es analizada en los tres artículos publicados a continuación. Por un lado, Ana Casas se centra en los juegos irónicos, paródicos y satíricos que llevan a cabo, entre otros, Woody Allen, Philip Roth o Charlie Kaufman, mientras que Aurora Piñeiro analiza los procesos de autoficcionalización en Joseph Anton: A memoir, de Salman Rushdie. Centrándose en el género poético, Anna Tort hace lo propio con la obra de Chantal Maillard, proponiéndonos una lectura transversal de su poética, desde 1995 hasta la actualidad. Las tres nos demuestran la estrecha relación entre los Estudios Autoriales y los estudios sobre la autoficción y, en general, la autografía: los marcos teóricos que proponen se añaden así al amplio abanico de perspectivas que contribuyen a comprender la instancia autorial y sus textualizaciones.

Finalmente, el último bloque de este monográfico abre otro ámbito de análisis imprescindible en la actualidad: el de la autoría en la era digital, abordando desde los hipertextos hasta los selfies, hoy tan en boga. La consideración de la autoría hipertextual como materialización de las teorías postestructuralistas sobre la muerte del autor está en disputa en el trabajo de Morrison, quién recurre al siglo XIII, y concretamente a la obra de San Buenaventura, para discutir su especificidad. Proponiendo un estudio de caso de estos géneros hipertextuales, María Goicoechea de Jorge se centra en la obra de Shelley Jackson, recuperando la reflexión en torno a la relación entre cuerpo y corpus autorial a través de My Body - A Wunderkammer. Para acabar, Jéssica Faciabén aborda la cuestión desde otro corpus de análisis en el que sin duda el cuerpo es de nuevo el protagonista: los selfies, analizados desde la teoría fotográfica de Barthes o Sontag.

La generosidad de todos/as estos/as investigadores/as y de los editores de Tropelías, Túa Blesa, Juan Carlos Pueo y Alfredo Saldaña, así como el cuidadoso trabajo realizado por las traductoras y la correctora que han colaborado en su elaboración, Michelle Gama, Carole Gouaillier y Mar Valldeoriola, han hecho posible «La autoría a debate», donde esperamos ofrecer una degustación de este apasionante campo de estudio. Gracias a ellos/as, estamos un poco más cerca de cumplir nuestro deseo, el de contribuir en alguna medida a los Estudios Autoriales actuales, y vemos más paliada esa 
12 Tropelías. Revista de Teoría de la Literatura y Literatura Comparada, 24 (2015)

Aina Pérez Fontdevila y Meri Torras Francès

necesidad a la que aludíamos al inicio: la de situarlos en el ámbito académico hispánico. Vaya pues, para ellos/as, nuestro especial reconocimiento.

\section{Bibliografía}

A.A.V.V. (2011): «La posture. Genèse, usages et limites d'un concept» [dossier monográfico], COnTEXTES. Revue de sociologie de la littérature, 8. [En http://contextes.revues.org/4692]

Amossy, R., ed. (2009): «La double nature de l'image d'auteur», Argumentation et Analyse du Discours, 3 [http://aad.revues.org/656]. [«La doble naturaleza de la imagen de autor», en J. Zapata, ed. La invención del autor. Nuevas aproximaciones al estudio sociológico y discursivo de la figura autorial. Trad. de J. Zapata. Medellín, Editorial Universidad de Antioquia, 2014, pp. 67-84].

(1999): Images de soi dans le discours. La construction de l'ethos. Lausana, Delachaux et Niestlé.

BARTHES, R. (1968): «La mort de l'auteur», Mantéia, 5, pp. 12-17 [«La muerte del autor», en El susurro del lenguaje. Más allá de la palabra y la escritura. Trad. de C. Fernández Medrano. Barcelona, Paidós, 1987, pp. 65-71].

(1971): Sade, Fourier, Loyola. París, Seuil. [Sade, Fourier, Loyola. Trad. de A. Martorell. Madrid, Cátedra, 1997]

(1975): Roland Barthes par Roland Barthes. París. [Roland Barthes por Roland Barthes. Trad. de J. Sucre. Barcelona, Paidós, 2004]

BÉNICHOU, P. (1973): Le sacre de l'écrivain, 1750-1830. Essai sue l'avènement d'un pouvoir spirituel läque dans la France moderne. París, Corti. [La coronación del escritor 1750-1830. Ensayo sobre el advenimiento de un poder espiritual laico en la Francia moderna. Trad. de A. Garzón del Camino. México, Fondo de Cultura Económica, 2012]

Berensmeyer, I., Buelens, G. y Demoor, M. (2012): «Authorship as Cultural Performance: New Perspectives in Authorship Studies», ZAA. Zeitschrift für Anglistik und Amerikanistik. A Quarterly of Language, Literature and Culture, 60/1, pp. 5-29. [«La autoría como performance cultural: nuevas perspectivas en estudios autoriales», en A. Pérez Fontdevila y M. Torras Francès, eds. Los papeles del autor/a. Teorías sobre autoría literaria. Trad. de M. Gama. Madrid, Arco Libros, 2015 (en prensa)].

Bertrand, J.-P., DuRAND, P., y LAVAud, M., dirs. (2010): «Le portrait photographique d'écrivain» [dossier monográfico], COnTEXTES. Revue de sociologie de la littérature, 14 [http://contextes.revues.org/5904].

BoKoBZA KAHAN, M. y AMOSsy, R., dirs. (2009): «Ethos discursif et image d'auteur» [dossier monográfico], Argumentation et Analyse du Discours, 3 [http://aad.revues.org/656].

BURKE, S. (1998): The Death and Return of the Author: Criticism and Subjectivity in Barthes, Foucault and Derrida. Edimburgo, Edinburgh University Press.

BUTLER, J. (1990): El género en disputa. México D.F, Paidós, 2001. 
(1997a): Lenguaje, poder e identidad. Madrid, Síntesis, 2004.

(1997b): Mecanismos psíquicos del poder: teorías sobre la sujeción. Madrid, Cátedra, 2001.

CRÓQUeR PEDRÓN, E. (2005): «Poner el cuerpo/hacer semblante: algunas consideraciones en torno a Ła Autor(a) latinoamericana», en C. Días Orozco, comp. Mirar las grietas: diálogos interculturales en la Venezuela contemporánea. Mérida, Publicaciones del Vicerrectorado Académico de la Universidad de Los Andes, pp. 111-122.

(2009): Escrito con rouge. Delmira Agustini (1886-1914). Artefacto cultural. Rosario, Beatriz Biterbo.

(2012): «Casos de autor: anormales/originales de la literatura y el arte (II). Allí donde la vida (es) obra», Voz y Escritura. Revista de Estudios Literarios, 20, pp. 89-103.

— - PÉrez Fontdevila, A. y Torras Francès, M., eds. (2015): «Autoría y género» [dossier monográfico], Mundo Nuevo. Revista Latinoamericana, 15.

— PÉrez Fontdevila, A. y TORRAs FrancÈs, M., eds. (2015): «Autoría y cuerpo» [dossier monográfico], Estudios. Revista de Investigaciones Literarias y Culturales, 42.

DERrIDA, J. (1981): «Les morts de Roland Barthes», Poétique, 47. [Las muertes de Roland Barthes. Trad. de Raymundo Mier. México, Taurus, 1998].

Dewez, N. y MARTENS, D., eds. (2009): «Iconographies de l'écrivain»[dossier monográfico], Interférences littéraires, 2 [http://www.interferenceslitteraires.be/nr2].

Dhondt, R., Horemans, K., Vanacker, B. y Vandemeulebroucke, K., dirs. (2013): «L'ethos en question. Effets, contours et perspectives» [dossier monográfico], COnTEXTES. Revue de sociologie de la littérature, 13 [http://contextes.revues.org/5674].

DiAZ, J.-L (1984): «Roland Barthes et la question de l'auteur», Textuel, 15, pp. 44-51 [«Muerte y resurrección del autor», en A. Pérez Fontdevila y M. Torras Francès, eds. Los papeles del autor/a. Teorías sobre autoría literaria. Trad. de A. Pérez. Madrid, Arco Libros, 2015 (en prensa)].

(1993): «L’écrivain comme fantasme», en C. Coquio y R. Salado, dirs. Barthes après Barthes, une actualité en question. Pau, Presses Universitaires de Pau, pp. 77-87.

(1996): «Roland Barthes par Roland Barthes ou Le fantôme de l'auteur», en Á. Sirvent, J. Bueno y S. Caporale, eds. Autor y texto: fragmentos de una presencia. Barcelona, PPU, pp. $57-$ 79 .

(2007a): L'écrivain imaginaire: scénographies auctoriales à l'époque romantique. París, Champion.

(2007b): Devenir Balzac. L'invention de l'écrivain par lui-même. Saint Cyr sur Loire, Christian Pirot.

(2011): «La noción de autor (1750-1850) », Literatura: teoría, historia, crítica, 13/2. Trad. de

J. M. Zapata. pp. 209-234.

_ (2012): L'Homme et l'oeuvre. París, Presses Universitaires de France. 
(2013): «Les scénographies auctoriales romantiques et leur "mise en discours"», en P. Delormas, D. Maingueneau y I. Østenstad, eds. Se dire écrivain. Practiques discursives de la mise en scène de soi. Limoges, Lambert-Lucas, pp. 29-50. [«Las escenografías autoriales románticas y su "puesta en discurso"», en A. Pérez Fontdevila y M. Torras Francès, eds. Los papeles del autor/a. Teorías sobre autoría literaria. Trad. de M. Torras. Madrid, Arco Libros, 2015 (en prensa)].

Even-Zohar, I. (1997): «Factors and Dependencies in Culture: A Revised Draft for Polysystem Culture Research», Canadian Review of Comparative Literature, XXIV, pp. 15-34. [«Factores y dependencias de la cultura. Una revisión de la Teoría de los Polisistemas», en M. Iglesias Santos, ed. Teoría de los Polisistemas. Madrid, Arco-Libros, 1999].

Foucault, M. (1969): «Qu’ est-ce qu’ un auteur? », Bulletin de la Société Francaise de Philosophie, 63/3 pp. 73-104. [¿Qué es un autor? Trad. de C. Iturbe. México, Universidad Autónoma de Tlaxcala y La Letra Ediciones, 1990].

Girona Fibla, N. (2008): Rituales de la verdad. Mujeres y discursos en América Latina. México y París, RILMA 2 / ADEHL.

Fuss, D. (1989): «Reading Like a Feminist», en Essentially Speaking. Londres, Routledge, 1989, pp. 23-37. [«Leer como una feminista», en N. Carbonell y M. Torras, eds. Feminismos literarios. Trad. de Pilar Godayol. Madrid, Arco Libros, 1999].

HeInICH, N. (2000): Être écrivain. Création et identité. París, La Découverte.

- (2005): L'élite artiste, excellence et singularité en régime démocratique. París, Gallimard. (2012): De la visibilité. Excellence et singularité en régime médiatique. París, Gallimard.

—, SChaEfFer J.M. y TALON-HugOn, C. (2014): Par-delà le beau et le laid. Enquêtes sur les valeurs de l'art. Rennes, Presses Universitaires de Rennes.

KAMUf, P. (1988): Signature pieces. On the Institution of Authorship. Ithaca y Londres, Cornell University Press. [Prefacio e introducción traducidos como «Una sola línea dividida», en A. Pérez Fontdevila y M. Torras Francès, eds. Los papeles del autor/a. Teorías sobre autoría literaria. Trad. de M. Gama y A. Pérez. Madrid, Arco Libros, 2015 (en prensa)].

LECLERC, G. (1998): Le sceau de l'oeuvre. París, Seuil.

Maingueneau, D. (1993): Le Contexte de l'oeuvre littéraire: énonciation, écrivain, société. París, Dunod.

(1996): «El ethos y la voz de lo escrito». Trad. de R. Alvarado. Version, 6, pp. 78-92. (2004): Le discours littéraire. Paratopie et scène d'énonciation. París, Armand Colin. (2006): Contre Saint Proust, ou la fin de la Littérature. París, Belin. (2009): «Auteur et image d'auteur en analyse du discours», Argumentation et Analyse du Discours, 3. [«Autor e imagen de autor en análisis del discurso», en J. Zapata, ed., La invención del autor. Nuevas aproximaciones al estudio sociológico y discursivo de la figura autorial. Trad. de Juan Zapata. Medellín, Editorial Universidad de Antioquia, pp. 49-66]. 
(2010): «El enunciador encarnado: La problemática del Ethos». Trad. de R. Alvarado. Versión, 24, pp. 203-225.

Martens, D. y ReVerseau, A. dirs. (2012): «Figurations iconographiques de l'écrivain» [dossier monográfico], Image and narrative, 13/4.

_ y M. WAtTheE-Delmotte (dirs.) (2012): L'écrivain, un objet culturel. Dijon, Éditions Universitaires de Dijon.

— y C. MEURÉE (2014): Secrets d'écrivains. Enquête sur les entretiens littéraires. Bruselas, Les Impressions Nouvelles.

- y C. MeuréE (2015): «Ceci n'est pas une interview. Littérarité conditionnelle de l'entretien d'écrivain», Poétique, 177, pp. 113-130.

dir. (2016): La Pseudonymie dans la littérature française. De François Rabelais à Éric Chevillard. Rennes, Presses Universitaires de Rennes, 2016 (en prensa).

MeIzoz, J. (2007): Postures littéraires. Mises en scène modernes de l'auteur. Ginebra-París, Slatkin

Erudition. [Posturas literarias: puestas en escena modernas del autor. Trad. de J. M. Zapata. Bogotá, Editorial Universidad de los Andes, 2015]

(2011): La fabrique des singularités. Postures Littéraires II. Ginebra-París, Slatkin Erudition. (2015): «“Écrire, c’est entrer en scène”: la littérature en personne», COnTEXTES. Revue de sociologie de la littérature, Varia [http://contextes.revues.org/6003]. [«"Escribir, es entrar en escena»": la literatura en persona». Trad. de J. M. Zapata. Estudios. Revista de investigaciones literarias y culturales, 42, 2015].

ORTEL, P. (2002): «Le portrait de l'écrivain», en La littérature à l'ère de la photographie. Enquête sur une révolution invisible. Nîmes, Jacqueline Chambon, pp. 277-282.

Oster, D. (1983): Passages de Zénon. Essai sur l'espace et les croyances littéraires. París, Seuil.

(1997): L'individu littéraire. París, Presses Universitaires de France.

PÉrez FontdeVIla A. y TORRAS FrAnCÈs, M., eds. (2015): Los papeles del autor/a. Teorías sobre la autoría literaria. Madrid, Arco Libros.

Premat, J. (2009): Héroes sin atributos. Figuras de autor en la literatura argentina. Buenos Aires, Fondo de Cultura Económica.

STANFORTD FRIEDMAN, S. (1987): «Creativity and the childbirth metaphor: gender difference in literary discourse», Feminist Studies, 13/1, 1987.

SCHAEFFER, J. M (1997): «Originalité et expression de soi. Éléments pour une généalogie de la figure moderne de l'artiste», Communications, 64, pp. 89-115. [«Originalidad y expresión de sí. Elementos para una genealogía de la figura moderna del artista», en A. Pérez Fontdevila y M. Torras Francès, eds. Los papeles del autor/a. Teorías sobre autoría literaria. Madrid, Arco Libros, 2015 (en prensa)].

Viala, A. (1985): Naissance de l'écrivain. Sociologie de la littérature à l'âge classique. París, Minuit. Woodmansee, M. (1984): «The Genius and the Copyright: Economic and Legal Conditions of the Emergence of the "Author”», Eighteenth-Century Studies, 17/4, pp. 425-448. [«El Genio y el 
16 Tropelías. Revista de Teoría de la Literatura y Literatura Comparada, 24 (2015)

Aina Pérez Fontdevila y Meri Torras Francès

copyright: condiciones económicas y legales de la emergencia del "autor"», en A. Pérez Fontdevila y M. Torras Francès, eds. Los papeles del autor/a. Teorías sobre autoría literaria. Trad. de M. Gama. Madrid, Arco Libros, 2015 (en prensa)].

(1994): The Author, Art, and the Market: Rereading the History of Aesthetics. Nueva York, Columbia University Press.

- y JASZI, P., eds. (1994): The Construction of Authorship. Durham, Duke University.

YANOSHEVsKy, G., dir. (2014): «L'entretien littéraire» [dossier monográfico], Argumentation et Analyse du Discours, 12 [http://aad.revues.org/1622].

ZAPATA, J. M. (2011): «Muerte y resurrección del autor: nuevas aproximaciones al estudio sociológico del autor», Lingüística y Literatura, 60, pp. 35-58.

(2014): La invención del autor. Nuevas aproximaciones al estudio sociológico y discursivo de la figura autorial. Medellín, Editorial Universidad de Antioquia. 